\title{
Antipsychotic Medication and Risk of QTc Prolongation: Focus on Multiple Medication and Role of Cytochrome P450 Isoforms
}

\author{
Takashi Ikeno ${ }^{1,2 *}$, Kiyotaka Kugiyama², Hiroto Ito ${ }^{1,2}$ \\ ${ }^{1}$ Department of Social Psychiatry, National Institute of Mental Health, National Center of Neurology and \\ Psychiatry, Tokyo, Japan \\ ${ }^{2}$ Faculty of Medicine, Graduate School of Medical Science, University of Yamanashi, Yamanashi, Japan \\ Email: ${ }^{\text {ikenot@ncnp.go.jp }}$
}

Received 11 August 2014; revised 6 September 2014; accepted 8 October 2014

Copyright (C) 2014 by authors and Scientific Research Publishing Inc.

This work is licensed under the Creative Commons Attribution International License (CC BY). http://creativecommons.org/licenses/by/4.0/

(c) (i) Open Access

\begin{abstract}
Objective: To identify the effects of antipsychotics on QTc prolongation in light of age, gender, antipsychotic combination pattern, antipsychotic doses and cytochrome P450 (CYP) mediation, using large database describing the antipsychotic treatment of patients with schizophrenia in Japan. Methods: Using database of $\mathbf{4 1 7 6}$ patients with schizophrenia discharged between April 2004 and March 2005 and receiving outpatient treatment from 526 psychiatric hospitals in Japan. Of the patients, 1437 were included for the analysis. These patients were classified into three groups according to the antipsychotic CPZ-equivalent doses that they received (low, 1 - $299 \mathrm{mg}$; middle, 300 $999 \mathrm{mg}$; and high, $\geq 1000 \mathrm{mg}$ ). QTc intervals $\geq 440 \mathrm{msec}$ were considered prolonged. We reviewed all the package inserts of the antipsychotics used from the website of Pharmaceuticals and Medical Devices Agency. Results: The mean QTc interval of the total patient group was $410.4 \pm 23.3 \mathrm{msec}$. The females had significantly higher QTc values than the males $(414.5 \pm 24.0$ vs. $406.8 \pm 22.2 \mathrm{msec}$, respectively; $\mathbf{p}<0.05$ ). Logistic regression analysis revealed that female gender (odds ratio $[\mathrm{OR}]=$ 1.83; 95\% CI: 1.28 - 2.56), CYP3A4-metabolized drugs (OR 1.56; 95\% CI: 1.05 - 2.30) were associated with an increased risk of QTc prolongation. Conclusion: The co-prescription of CYP3A4-mediated antipsychotic drugs should be carefully considered in females due to potential risk of QTc prolongation. Further studies of the cardiovascular safety of antipsychotics are warranted in patients receiving multiple medications.
\end{abstract}

\section{Keywords}

Antipsychotics, CYP, Drug Interaction, QTc Prolongation, Schizophrenia

\footnotetext{
${ }^{*}$ Corresponding author.
}

How to cite this paper: Ikeno, T., Kugiyama, K. and Ito, H. (2014) Antipsychotic Medication and Risk of QTc Prolongation: Focus on Multiple Medication and Role of Cytochrome P450 Isoforms. Open Journal of Psychiatry, 4, 381-389. 


\section{Introduction}

Concern about cardiac safety is a leading cause for the withdrawal of several marketed drugs. The International Conference on Harmonisation of Technical Requirements for Registration of Pharmaceuticals for Human Use (ICH) has developed guidelines (E14) to assess corrected QT (QTc) prolongation, which can lead to lifethreatening cardiac arrhythmia or torsade de pointes [1]. The QTc interval represents the duration of ventricular depolarization and subsequent repolarization, and a delay in cardiac repolarization can be measured as prolongation of the QTc interval by electrocardiography (ECG). The QTc interval is used as a surrogate marker for the prediction of serious adverse drug effects, syncope, or death due to torsade de pointes [2].

Drugs that cause prolongation of the QTc interval have been extensively studied in the past decade [3]-[13]. Antipsychotics have been known to be associated with QTc prolongation, as have drugs such as antidysrhythmics and antibiotics [6] [9]. The use of antipsychotics is a first-line treatment for psychotic disorders such as schizophrenia. Some of the typical antipsychotics that are in use today have been available since the 1950s, and atypical antipsychotics have been used since the 1990s as the second-generation medications for psychotic disorders [4]. Thioridazine (a typical antipsychotic) and ziprasidone (an atypical antipsychotic) were withdrawn from the market due to the increased risk of QTc prolongation and sudden death that they presented [14] [15]. Antipsychotic medications are commonly prescribed off-label for conditions such as delirium and autism spectrum disorder, in populations including the elderly and children [16]. The increased risk of death in elderly patients has been reported regarding both typical and atypical antipsychotics [17].

In clinical practice, more than one drug is often prescribed concurrently, and combination-drug treatment is a common prescription pattern of antipsychotics in psychiatry [18]-[20]. Although co-prescribing can be appropriate, the interaction of multiple drugs may increase the risk of adverse effects by pharmacokinetic and pharmacodynamic interactions. One drug may alter the other's absorption, distribution, metabolism, and/or excretion with a pharmacokinetic interaction, and two drugs may have additive, synergistic, and/or antagonistic effects with a pharmacodynamic interaction [21].

In efforts to predict clinically relevant drug interactions, the cytochrome P450 (CYP) system is important; the system's six enzymes (CYP 1A2, 2C9, 2C19, 2D6, 2E1 and 3A4) metabolize more than 90\% of the existing drugs [22]. When two drugs sharing the same metabolic pathway compete for the same enzyme receptor site, enzyme inhibition occurs, and the plasma level of the unmetabolized drug is enhanced because the predominant inhibitor decreases the metabolism of the competing drug, leading to a greater potential for toxicity [23].

Adverse cardiovascular effects due to drug interactions are of great concern, but the effects of combined drugs on QTc prolongation have not been clarified. The objective of the present study was to identify the effects of antipsychotics on QTc prolongation in light of age, gender, antipsychotic combination pattern, antipsychotic doses and CYP mediation, using a large database of antipsychotic treatment of patients with schizophrenia in Japan.

\section{Methods}

\subsection{Data Sources}

A retrospective study was conducted using the database from a nationwide study conducted by the Japan Psychiatric Hospitals Association (JPHA) in 2007. Of the 1215 member hospitals of the JPHA, 526 hospitals (43.3\%) participated in the original study to examine the effects of daycare services for patients with schizophrenia who were discharged between April 2004 and March 2005 and who continued to receive outpatient treatment at the hospitals [24] [25]. Using a systematic sampling technique, every fifth patient was selected from the medical records of the total 21,396 patients $(n=4176)$. QTc was measured during the patient's hospitalization at psychiatric hospitals. The database includes sociodemographics, diagnosis, and prescription drug and QTc information.

\subsection{Study Population}

In the present study, patients with following available data were included: 1) age, 2) gender, 3) QTc interval during hospitalization, and 4) prescription information of the antipsychotics used by the patients. Exclusion criteria were: 1) aged under 20 or over 99 years old, 2) history of myocardial infarction or angina, 3) patients whose QTc were monitored only at admission, 4) QTc under $360 \mathrm{msec}$ or over $600 \mathrm{msec}$, 5) antipsychotic monotherapy, and 6) antipsychotics without any information on CYP. After 2598 patients were excluded based 
on these criteria, 1437 patients were included for the analysis.

QTc-interval measurements were generated by a computer algorithm at each participating hospital. In the present study, QTc intervals $\geq 440$ msec were considered prolonged [26] [27]. All antipsychotic doses were converted to chlorpromazine equivalent (CPZ-equivalent) [28]. In general, $300 \mathrm{mg}$ to $999 \mathrm{mg}$ is known as the recommended dose of an antipsychotic CPZ-equivalent drug [19] [29]. In the present study, the patients were classified into three groups according to the CPZ-equivalent antipsychotic dose they had been prescribed: 1 $299 \mathrm{mg}$ as the low-dose group ( $\mathrm{n}=119), 300-999 \mathrm{mg}$ as the middle-dose group ( $\mathrm{n}=789)$, and $\geq 1000 \mathrm{mg}$ as the high-dose group $(\mathrm{n}=529)$. QTc intervals were studied by drug combination patterns (typical + typical, typical + atypical, and atypical + atypical antipsychotics).

We examined the cardiac effects of combined antipsychotics that were metabolized by the same CYP system. We reviewed all of the package inserts of antipsychotics from the website of Japan's Pharmaceuticals and Medical Devices Agency (PMDA), and all of the relevant articles in scientific journals on CYP isoforms and QTc interval information of antipsychotics (Table 1) [3] [15] [22] [26] [30]-[50].

\subsection{Statistical Analysis}

Mean and standard deviation (SD) were used to represent distribution of continuous variables. We used Student's t-test and one-way analysis of variance (ANOVA) to compare QTc prolongation group (QTc $\geq 440 \mathrm{msec}$ ) and control group (QTc $<440 \mathrm{msec}$ ). Multiple logistic regression analysis was performed to assess factors that could contribute to QTc interval prolongation. Age, gender, and CYP groups (1A2, 2D6 and 3A4) were included in the forced entry method. Only the significant variables were included when comparing the dichotomized QTc intervals ( $\geq 440 \mathrm{msec}$ vs. $<440 \mathrm{msec}$ ). All statistical analyses were performed using SPSS version 18.0 for Windows (SPSS Inc., Chicago, IL). p-values $<0.05$ were accepted as significant.

\section{Table 1. CYP isoforms and QTc interval of antipsychotics.}

\begin{tabular}{|c|c|c|}
\hline Drug name & Antipsychotic class & CYP $^{\mathrm{a}}$ isoform \\
\hline \multicolumn{3}{|l|}{ Known to prolong the QTc interval } \\
\hline Bromperidol [51] & Typical & $3 \mathrm{~A} 4[47]$ \\
\hline Chlorpromazine [26] [52] & Typical & 2D6 [38] \\
\hline Fluphenazine decanoate [53] [54] & Typical & 2D6 [50] \\
\hline Haloperidol [55] [56] & Typical & $2 \mathrm{D} 6[50]$ \\
\hline Haloperidol decanoate [52] [57] & Typical & $2 \mathrm{D} 6[34][48]$ \\
\hline Levomepromazine [52] [58] & Typical & 2D6 [49] \\
\hline Nemonapride [59] & Typical & 2D6 [30] \\
\hline Olanzapine [60] [61] & Atypical & 1A2, 2D6 [45] \\
\hline Perphenazine [8] [40] & Typical & 2D6 [45] \\
\hline Pimozide [41] [62] & Typical & $1 \mathrm{~A} 2,2 \mathrm{D} 6,3 \mathrm{~A} 4[33]$ \\
\hline Quetiapine [42] [60] & Atypical & 3A4 [4] [35] \\
\hline Risperidone [60] [63] & Atypical & 2D6 [32] \\
\hline Trifluoperazine [64] & Typical & $1 \mathrm{~A} 2[44]$ \\
\hline \multicolumn{3}{|l|}{ No available information on QTc interval } \\
\hline Perospirone & Atypical & 1A2, 2C8, 2D6, 3A4 [5] \\
\hline Zotepine & Atypical & 1A2, 2B6, 2C9, 2C19, 2D6, 3A4, 3A5 [5] \\
\hline
\end{tabular}

${ }^{\mathrm{a} C Y P}$ : cytochrome P450. 


\subsection{Ethical Considerations}

The study protocol was approved by the Institutional Review Boards of the JPHA and National Center of Neurology and Psychiatry (NCNP). The study protocol has been registered in the UMIN Clinical Trials Registry (UMIN-CTR) in Japan (UMIN000010473).

\section{Results}

The mean QTc interval of the total group of patients was $410.4 \pm 23.3$ msec (Table 2). The females $(\mathrm{n}=670)$ had significantly longer than QTc intervals compared to the males $(n=767)(414.5 \pm 24.0$ vs. $406.8 \pm 22.2 \mathrm{msec}$, respectively; $p<0.05$ ). There were no significant differences in QTc intervals among the three dose groups or among the different drug combination patterns.

The results of the logistic regression analysis examining the risk factors of QTc interval prolongation are presented in Table 3. Females were more susceptible to QTc prolongation than men (odds ratio [OR] = 1.83; 95\% CI: 1.28 - 2.56). CYP3A4-mediated antipsychotics were more likely to prolong the QTc interval compared to non-CYP3A4-mediated antipsychotics (OR 1.56; 95\% CI: 1.05 - 2.30). CYP1A2-mediated antipsychotics were less likely to prolong the QTc interval compared to non-CYP1A2-mediated antipsychotics (OR 0.65; 95\% CI: 0.44 - 0.97).

\section{Discussion}

The present study revealed that patients receiving combined antipsychotics that were metabolized by the CYP3A4 had longer QTc intervals than those receiving drugs that were metabolized by different pathways. The female patients were significantly more susceptible to QTc prolongation than the males. Antipsychotic dosing and typical/atypical combination patterns were not associated with QTc prolongation.

Although a recent study demonstrated that the use of combined antipsychotics did not increase the risk of sudden cardiac death or ventricular arrhythmia [12], the present analysis indicates that combined CYP3A4-mediated antipsychotics may be a risk factor for QTc prolongation. The results showed that the QTc interval was

Table 2. Mean QTc interval and patient characteristics.

\begin{tabular}{|c|c|c|}
\hline & n (\%) & Mean QTc \pm SD (msec) \\
\hline Overall & $1437(100)$ & $410.4 \pm 23.3$ \\
\hline \multicolumn{3}{|l|}{ Gender } \\
\hline Male & 767 (53.4) & $406.8 \pm 22.2$ \\
\hline Female & $670(46.6)$ & $414.5 \pm 24.0^{*}$ \\
\hline \multicolumn{3}{|l|}{ Age (years) } \\
\hline$<65$ & $1290(89.8)$ & $409.9 \pm 23.1$ \\
\hline$>65$ & $147(10.2)$ & $414.7 \pm 25.3$ \\
\hline \multicolumn{3}{|l|}{$\mathrm{CPZeq}^{\mathrm{a}}$} \\
\hline $1 \mathrm{mg}-299 \mathrm{mg}$ & 119 (8.3) & $406.2 \pm 24.0$ \\
\hline 300 mg - 999 mg & 789 (54.9) & $411.2 \pm 22.1$ \\
\hline$\geq 1000 \mathrm{mg}$ & $529(36.8)$ & $410.1 \pm 24.9$ \\
\hline \multicolumn{3}{|l|}{ Combination pattern } \\
\hline Typical + typical & 451 (31.4) & $408.4 \pm 23.2$ \\
\hline Typical + atypical & $880(61.2)$ & $411.3 \pm 23.5$ \\
\hline Atypical + atypical & $106(7.4)$ & $411.3 \pm 21.6$ \\
\hline
\end{tabular}

${ }^{\mathrm{a}}$ CPZeq: chlorpromazine equivalent. ${ }^{*} \mathrm{p}<0.05$. 
Table 3. Risk factors of QTc prolongation by logistic regression.

\begin{tabular}{|c|c|c|c|c|}
\hline & n (\%) & QTc prolongation (\%) & Odds ratio (95\% CI) & $\mathrm{p}$ value \\
\hline \multicolumn{5}{|l|}{ Gender } \\
\hline Female & $670(46.6)$ & 89 (13.3) & $1.83(1.28-2.56)$ & 0.001 \\
\hline Male & $767(53.4)$ & $59(7.7)$ & 1.00 & \\
\hline \multicolumn{5}{|l|}{ Age (years) } \\
\hline$<65$ & $1290(89.8)$ & $131(10.2)$ & $1.06(0.61-1.83)$ & 0.846 \\
\hline$>65$ & $147(10.2)$ & $17(11.6)$ & 1.00 & \\
\hline \multicolumn{5}{|l|}{ CYP 1A2 } \\
\hline CYP 1A2-mediated drugs & $637(44.3)$ & $58(9.1)$ & $0.65(0.44-0.97)$ & 0.033 \\
\hline Non CYP 1A2-mediated drugs & 800 (55.7) & 90 (11.3) & 1.00 & \\
\hline \multicolumn{5}{|l|}{ CYP 2D6 } \\
\hline CYP 2D6-mediated drugs & $1414(98.4)$ & $145(10.3)$ & $0.94(0.27-3.33)$ & 0.925 \\
\hline Non CYP 2D6-mediated drugs & $23(1.6)$ & $3(13.0)$ & 1.00 & \\
\hline \multicolumn{5}{|l|}{ CYP 3A4 } \\
\hline CYP 3A4-mediated drugs & 574 (39.9) & $68(11.8)$ & $1.56(1.05-2.30)$ & 0.026 \\
\hline Non CYP 3A4-mediated drugs & $863(60.1)$ & $80(9.3)$ & 1.00 & \\
\hline
\end{tabular}

${ }^{\mathrm{a}}$ Number of patients with QTc $\geq 440$ msec.

prolonged in patients receiving CYP3A4-mediated antipsychotic combinations. Ray et al. studied the potential relationship between macrolide antimicrobial agent and sudden death, and they concluded that the concurrent use of erythromycin and strong inhibitors of CYP3A4 should be avoided [43].

Several studies support the finding of a gender difference, i.e., that female patients are at greater risk of QTc prolongation [7] [12]. The gender difference in QTc prolongation may be related to sex hormones [65] [66]. The QTc interval is similar in children aged younger than 15 years before puberty, but the QTc interval in males decreases after puberty, resulting in longer QTc intervals in females [67]. Testosterone may be related to the difference, and gender-specific medication therapy should be considered [36].

Also, the antipsychotic dosing and typical/atypical combinations were not associated with QTc prolongation in the present study. Regarding the dosing, the results of previous studies have been contradictory; one study reported that high doses presented a risk of QTc prolongation [7], whereas another suggested there was no association [12]. Ozeki et al. reported that the first-generation antipsychotics partly contributed to QTc prolongation, and the second-generation antipsychotics presented a relatively low risk of fatal arrhythmia [52].

Despite the documented abnormal QTc, the rate of serious cardiovascular effects is low [31]. QTc prolongation in a schizophrenic population cannot directly address clinically relevant issues of cardiovascular adverse effects due to acceptable small extensions, and the risk of sudden death is likely to be small in these data. The definitions of the QTc prolongation vary, and QTc intervals are different in males and females. When the QTc interval exceeds $500 \mathrm{msec}$, it implies clinical significance in both males and females [14]. Because the subjects of the present study were not patients with pre-existing cardiovascular conditions, $440 \mathrm{msec}$ was used as the cutoff point of the QTc prolongation for both the males and females.

However, caution is needed when a drug is known to prolong the QTc interval due to potential inhibition of its metabolism by another drug. In clinical practice, the avoidance or the minimum use of co-prescribed CYP3A4-metabolized antipsychotics should be considered.

There are several limitations to the present study. First, the database did not include information on predisposing factors including congenital long QTc syndrome and comorbidity, or for prescriptions for comorbidity such as for the presence of diabetes and the prescription of antidiabetic drugs. Second, the effects of potential confounders cannot be excluded. The CYP pathway of antipsychotic drugs have not all been revealed, and thus further studies are required before the present results could be generalized. Third, QTc may be considerably affected by blood concentration of the antipsychotic drugs. The time points of the daily administration of the drugs 
and measurement of QTc was unknown because we used the secondary data from the multicenter study. More sophisticated study is needed. Fourth, context of the time the antipsychotics and the time of measurement of the QTc was prescribed is unknown. Fifth, the study design is a retrospective open cohort study, so the observed associations should be interpreted carefully. It is believed that the timing of the prescription blood levels to be involved, and further study. Despite these limitations, the present findings highlight the potential CYP-mediated drug-drug interactions in combined antipsychotics revealed by using a large database, and our results will contribute to the risk management of drug-induced QTc prolongation.

\section{Conclusion}

The co-prescription of CYP3A4-mediated antipsychotic drugs should be carefully considered in females due to potential risk of QTc prolongation. Further studies of the cardiovascular safety of antipsychotics are warranted in patients receiving multiple medications.

\section{Acknowledgements}

We thank Dr. Ken Mayahara, Mr. Yoshio Matsumoto, Dr. Junichi Hirakawa, and the Health-Economics Committee of the Japanese Association of Psychiatric Hospitals for allowing the analysis of the Committee's research data. This research was funded by the Health and Labour Sciences Research Grant for Comprehensive Research on Disability Health and Welfare from the Japanese Ministry of Health, Labour, and Welfare.

\section{Competing Interests}

The authors declare that they have no competing interests.

\section{References}

[1] ICH Harmonized Tripartite Guideline E14 (2005) E14 Clinical Evaluation of QT/QTc Interval Prolongation and Proarrhythmic Potential for Non-Antiarrhythmic Drugs. http://www.fda.gov/downloads/RegulatoryInformation/Guidances/ucm129357.pdf

[2] Roden, D.M. (2004) Drug-Induced Prolongation of the QT Interval. The New England Journal of Medicine, 350, 1013-1022. http://dx.doi.org/10.1056/NEJMra032426

[3] Brown, C.S., Farmer, R.G., Soberman, J.E. and Eichner, S.F. (2004) Pharmacokinetic Factors in the Adverse Cardiovascular Effects of Antipsychotic Drugs. Clinical Pharmacokinetics, 43, 33-56. http://dx.doi.org/10.2165/00003088-200443010-00003

[4] Glassman, A.H. and Bigger Jr., J.T., (2001) Antipsychotic Drugs: Prolonged QTc Interval, Torsade de Pointes, and Sudden Death. American Journal of Psychiatry, 158, 1774-1782. http://dx.doi.org/10.1176/appi.ajp.158.11.1774

[5] Mackin, P. and Young, A.H. (2005) QTc Interval Measurement and Metabolic Parameters in Psychiatric Patients Taking Typical or Atypical Antipsychotic Drugs: A Preliminary Study. Journal of Clinical Psychiatry, 66, 1386-1391. http://dx.doi.org/10.4088/JCP.v66n1107

[6] Montanez, A., Ruskin, J.N., Hebert, P.R., Lamas, G.A. and Hennekens, C.H. (2004) Prolonged QTc Interval and Risks of Total and Cardiovascular Mortality and Sudden Death in the General Population: A Review and Qualitative Overview of the Prospective Cohort Studies. Archives of Internal Medicine, 164, 943-948. http://dx.doi.org/10.1001/archinte.164.9.943

[7] Reilly, J.G., Ayis, S.A., Ferrier, I.N., Jones, S.J. and Thomas, S.H. (2000) QTc-Interval Abnormalities and Psychotropic Drug Therapy in Psychiatric Patients. Lancet, 355, 1048-1052. http://dx.doi.org/10.1016/S0140-6736(00)02035-3

[8] Stollberger, C., Huber, J.O. and Finsterer, J. (2005) Antipsychotic Drugs and QT Prolongation. International Clinical Psychopharmacology, 20, 243-251. http://dx.doi.org/10.1097/01.yic.0000166405.49473.70

[9] Taylor, D.M. (2003) Antipsychotics and QT Prolongation. Acta Psychiatrica Scandinavica, 107, 85-95. http://dx.doi.org/10.1034/j.1600-0447.2003.02078.x

[10] van Noord, C., Straus, S.M., Sturkenboom, M.C., Hofman, A., Aarnoudse, A.J., Bagnardi, V., et al. (2009) Psychotropic Drugs Associated with Corrected QT Interval Prolongation. Journal of Clinical Psychopharmacology, 29, 9-15. http://dx.doi.org/10.1097/JCP.0b013e318191c6a8

[11] Warner, J.P., Barnes, T.R. and Henry, J.A. (1996) Electrocardiographic Changes in Patients Receiving Neuroleptic Medication. Acta Psychiatrica Scandinavica, 93, 311-313. http://dx.doi.org/10.1111/j.1600-0447.1996.tb10653.x 
[12] Yang, F.D., Wang, X.Q., Liu, X.P., Zhao, K.X., Fu, W.H., Hao, X.R., et al. (2011) Sex Difference in QTc Prolongation in Chronic Institutionalized Patients with Schizophrenia on Long-Term Treatment with Typical and Atypical Antipsychotics. Psychopharmacology, 216, 9-16. http://dx.doi.org/10.1007/s00213-011-2188-5

[13] Zemrak, W.R. and Kenna, G.A. (2008) Association of Antipsychotic and Antidepressant Drugs with Q-T Interval Prolongation. American Journal of Health-System Pharmacy, 65, 1029-1038. http://dx.doi.org/10.2146/ajhp070279

[14] Haddad, P.M. and Anderson, I.M. (2002) Antipsychotic-Related QTc Prolongation, Torsade de Pointes and Sudden Death. Drugs, 62, 1649-1671. http://dx.doi.org/10.2165/00003495-200262110-00006

[15] Khan, M.M., Logan, K.R., McComb, J.M. and Adgey, A.A. (1981) Management of Recurrent Ventricular Tachyarrhythmias Associated with Q-T Prolongation. American Journal of Cardiology, 47, 1301-1308. http://dx.doi.org/10.1016/0002-9149(81)90263-0

[16] Leslie, D.L. and Rosenheck, R. (2012) Off-Label Use of Antipsychotic Medications in Medicaid. The American Journal of Managed Care, 18, e109-e117.

[17] Wang, P.S., Schneeweiss, S., Avorn, J., Fischer, M.A., Mogun, H., Solomon, D.H., et al. (2005) Risk of Death in Elderly Users of Conventional vs. Atypical Antipsychotic Medications. The New England Journal of Medicine, 353, 2335-2341. http://dx.doi.org/10.1056/NEJMoa052827

[18] Ito, H., Okumura, Y., Higuchi, T., Tan, C.H. and Shinfuku, N. (2012) International Variation in Antipsychotic Prescribing for Schizophrenia: Pooled Results from the Research on East Asia Psychotropic Prescription (Reap) Studies. Open Journal of Psychiatry, 2, 340-346. http://dx.doi.org/10.4236/ojpsych.2012.224048

[19] Lelliott, P., Paton, C., Harrington, M., Konsolaki, M., Sensky, T. and Okocha, C. (2002) The Influence of Patient Variables on Polypharmacy and Combined High Dose of Antipsychotic Drugs Prescribed for In-Patients. Psychiatric Bulletin, 26, 411-414. http://dx.doi.org/10.1192/pb.26.11.411

[20] Sim, K., Su, H.C., Fujii, S., Yang, S.Y., Chong, M.Y., Ungvari, G., et al. (2009) High-Dose Antipsychotic Use in Schizophrenia: A Comparison between the 2001 and 2004 Research on East Asia Psychotropic Prescription (REAP) Studies. British Journal of Clinical Pharmacology, 67, 110-117. http://dx.doi.org/10.1111/j.1365-2125.2008.03304.X

[21] Scott, R.P. (2010) Drug Interactions. NIH. http://www.cc.nih.gov/training/training/principles/slides/DrugInteractions2010-2011_text.pdf

[22] Rendic, S. (2002) Summary of Information on Human CYP Enzymes: Human P450 Metabolism Data. Drug Metabolism Reviews, 34, 83-448. http://dx.doi.org/10.1081/DMR-120001392

[23] Ogu, C.C. and Maxa, J.L. (2000) Drug Interactions Due to Cytochrome P450. Baylor University Medical Center Proceedings, 13, 421-423.

[24] Kobayashi, M., Ito, H., Okumura, Y., Mayahara, K., Matsumoto, Y. and Hirakawa, J. (2010) Hospital Readmission in First-Time Admitted Patients with Schizophrenia: Smoking Patients Had Higher Hospital Readmission Rate than Non-Smoking Patients. The International Journal of Psychiatry in Medicine, 40, 247-257. http://dx.doi.org/10.2190/PM.40.3.b

[25] Okumura, Y., Ito, H., Kobayashi, M., Mayahara, K., Matsumoto, Y. and Hirakawa, J. (2010) Prevalence of Diabetes and Antipsychotic Prescription Patterns in Patients with Schizophrenia: A Nationwide Retrospective Cohort Study. Schizophrenia Research, 119, 145-152. http://dx.doi.org/10.1016/j.schres.2010.02.1061

[26] Christensen, P.K., Gall, M.A., Major-Pedersen, A., Sato, A., Rossing, P., Breum, L., et al. (2000) QTc Interval Length and QT Dispersion as Predictors of Mortality in Patients with Non-Insulin-Dependent Diabetes. Scandinavian Journal of Clinical \& Laboratory Investigation, 60, 323-332. http://dx.doi.org/10.1080/003655100750046486

[27] Saarnivaara, L., Klemola, U.M., Lindgren, L., Rautiainen, P. and Suvanto, A. (1990) QT Interval of the ECG, Heart Rate and Arterial Pressure Using Propofol, Methohexital or Midazolam for Induction of Anaesthesia. Acta Anaesthesiologica Scandinavica, 34, 276-281. http://dx.doi.org/10.1111/j.1399-6576.1990.tb03085.x

[28] Inagaki, A. and Inada, T. (2006) Dose Equivalence of Psychotropic Drugs. Part 18: Dose Equivalence of Psychotropic Drugs: 2006-Version. Japanese Journal of Clinical Psychopharmacology, 9, 1443-1447. (in Japanese)

[29] Bazett, H.C. (1920) The Time Relations of the Blood-Pressure Changes after Excision of the Adrenal Glands, with Some Observations on Blood Volume Changes. The Journal of Physiology, 53, 320-339.

[30] Caccia, S. (2000) Biotransformation of Post-Clozapine Antipsychotics: Pharmacological Implications. Clinical Pharmacokinetics, 38, 393-414. http://dx.doi.org/10.2165/00003088-200038050-00002

[31] Crouch, M.A., Limon, L. and Cassano, A.T. (2003) Clinical Relevance and Management of Drug-Related QT Interval Prolongation. Pharmacotherapy, 23, 881-908. http://dx.doi.org/10.1592/phco.23.7.881.32730

[32] de Leon, J., Sandson, N.B. and Cozza, K.L. (2008) A Preliminary Attempt to Personalize Risperidone Dosing Using Drug-Drug Interactions and Genetics: Part II. Psychosomatics, 49, 347-361. http://dx.doi.org/10.1176/appi.psy.49.4.347 
[33] Desta, Z., Kerbusch, T., Soukhova, N., Richard, E., Ko, J.W. and Flockhart, D.A. (1998) Identification and Characterization of Human Cytochrome P450 Isoforms Interacting with Pimozide. Journal of Pharmacology and Experimental Therapeutics, 285, 428-437.

[34] Fang, J., Baker, G.B., Silverstone, P.H. and Coutts, R.T. (1997) Involvement of CYP3A4 and CYP2D6 in the Metabolism of Haloperidol. Cellular and Molecular Neurobiology, 17, 227-233. http://dx.doi.org/10.1023/A:1026317929335

[35] Grimm, S.W., Richtand, N.M., Winter, H.R., Stams, K.R. and Reele, S.B. (2006) Effects of Cytochrome P450 3A Modulators Ketoconazole and Carbamazepine on Quetiapine Pharmacokinetics. British Journal of Clinical Pharmacology, 61, 58-69. http://dx.doi.org/10.1111/j.1365-2125.2005.02507.x

[36] Lazarus, G.M. (2001) Gender-Specific Medicine in Pediatrics. The Journal of Gender-Specific Medicine, 4, 50-53.

[37] Mizuno, Y., Tani, N., Komuro, S., Kanamaru, H. and Nakatsuka, I. (2003) In Vitro Metabolism of Perospirone in Rat, Monkey and Human Liver Microsomes. European Journal of Drug Metabolism and Pharmacokinetics, 28, 59-65. http://dx.doi.org/10.1007/BF03190868

[38] Muralidharan, G., Cooper, J.K., Hawes, E.M., Korchinski, E.D. and Midha, K.K. (1996) Quinidine Inhibits the 7-Hydroxylation of Chlorpromazine in Extensive Metabolisers of Debrisoquine. European Journal of Clinical Pharmacology, 50, 121-128. http://dx.doi.org/10.1007/s002280050079

[39] Olesen, O.V. and Linnet, K. (2000) Identification of the Human Cytochrome P450 Isoforms Mediating in Vitro N-Dealkylation of Perphenazine. British Journal of Clinical Pharmacology, 50, 563-571. http://dx.doi.org/10.1046/j.1365-2125.2000.00298.x

[40] Perphenazine Package Insert (2013) http://www.info.pmda.go.jp/go/pack/1172006F1030_1_07/

[41] Pimozide Package Insert (2013) http://www.info.pmda.go.jp/go/pack/1179022C1034_1_07/

[42] Quetiapine Package Insert (2013) http://www.info.pmda.go.jp/go/pack/1179042C1023 2 14/

[43] Ray, W.A., Murray, K.T., Meredith, S., Narasimhulu, S.S., Hall, K. and Stein, C.M. (2004) Oral Erythromycin and the Risk of Sudden Death from Cardiac Causes. The New England Journal of Medicine, 351, 1089-1096. http://dx.doi.org/10.1056/NEJMoa040582

[44] Semla, T.P., Beizer, J.L. and Higbee, M.D. (2005) Geriatric Dosage Handbook. 10th Edition, Lexi Comp Inc, Hudson, 1286-1290.

[45] Sharif, Z.A. (2003) Pharmacokinetics, Metabolism and Drug-Drug Interactions of Atypical Antipsychotics in Special Populations. Journal of Clinical Psychiatry, 5, 22-25.

[46] Shiraga, T., Kaneko, H., Iwasaki, K., Tozuka, Z., Suzuki, A. and Hata, T. (1999) Identification of Cytochrome P450 Enzymes Involved in the Metabolism of Zotepine, an Antipsychotic Drug, in Human Liver Microsomes. Xenobiotica, 29, 217-229. http://dx.doi.org/10.1080/004982599238623

[47] Tateishi, T., Watanabe, M., Kumai, T., Tanaka, M., Moriya, H., Yamaguchi, S., et al. (2000) CYP3A Is Responsible for N-Dealkylation of Haloperidol and Bromperidol and Oxidation of Their Reduced Forms by Human Liver Microsomes. Life Sciences, 67, 2913-2920. http://dx.doi.org/10.1016/S0024-3205(00)00874-2

[48] Tyndale, R.F., Kalow, W. and Inaba, T. (1991) Oxidation of Reduced Haloperidol to Haloperidol: Involvement of Human P450IID6 (Sparteine/Debrisoquine Monooxygenase). British Journal of Clinical Pharmacology, 31, 655-660. http://dx.doi.org/10.1111/j.1365-2125.1991.tb05588.X

[49] Yukawa, E., Hokazono, T., Yukawa, M., Ichimaru, R., Maki, T., Matsunaga, K., et al. (2002) Population Pharmacokinetics of Haloperidol Using Routine Clinical Pharmacokinetic Data in Japanese Patients. Clinical Pharmacokinetics, 41, 153-159. http://dx.doi.org/10.2165/00003088-200241020-00006

[50] Zhou, S.F. (2009) Polymorphism of Human Cytochrome P450 2D6 and Its Clinical Significance: Part II. Clinical Pharmacokinetics, 48, 761-804. http://dx.doi.org/10.2165/11318070-000000000-00000

[51] Bromperidol Package Insert (2013) http://www.info.pmda.go.jp/go/pack/1179028C1066_2_11/

[52] Ozeki, Y., Fujii, K., Kurimoto, N., Yamada, N., Okawa, M., Aoki, T., et al. (2010) QTc Prolongation and Antipsychotic Medications in a Sample of 1017 Patients with Schizophrenia. Progress in Neuro-Psychopharmacology \& Biological Psychiatry, 34, 401-405. http://dx.doi.org/10.1016/j.pnpbp.2010.01.008

[53] Chong, S.A., Mythily, Lum, A., Goh, H.Y. and Chan, Y.H. (2003) Prolonged QTc Intervals in Medicated Patients with Schizophrenia. Human Psychopharmacology, 18, 647-649. http://dx.doi.org/10.1002/hup.540

[54] Fluphenazine Decanoate Package Insert (2013) http://www.info.pmda.go.jp/go/pack/1172405A1031_2_07/

[55] Beach, S.R., Celano, C.M., Noseworthy, P.A., Januzzi, J.L. and Huffman, J.C. (2013) QTc Prolongation, Torsades de Pointes and Psychotropic Medications. Psychosomatics, 54, 1-13. http://dx.doi.org/10.1016/j.psym.2012.11.001

[56] Haloperidol Package Insert (2013) http://www.info.pmda.go.jp/go/pack/1179020C1191_1_11/ 
[57] Haloperidol Decanoate Package Insert (2013) http://www.info.pmda.go.jp/go/pack/1179406A1037_2_09/

[58] Levomepromazine Package Insert (2013) http://www.info.pmda.go.jp/go/pack/1172014B2056_1_13/

[59] Nemonapride Package Insert (2013) http://www.info.pmda.go.jp/go/pack/1179036F1024_1_01/

[60] Harrigan, E.P., Miceli, J.J., Anziano, R., Watsky, E., Reeves, K.R., Cutler, N.R., et al. (2004) A Randomized Evaluation of the Effects of Six Antipsychotic Agents on QTc, in the Absence and Presence of Metabolic Inhibition. Journal of Clinical Psychopharmacology, 24, 62-69. http://dx.doi.org/10.1097/01.jcp.0000104913.75206.62

[61] Olanzapine Package Insert (2013) http://www.info.pmda.go.jp/go/pack/1179044F4028_1_18/

[62] Desta, Z., Kerbusch, T. and Flockhart, D.A. (1999) Effect of Clarithromycin on the Pharmacokinetics and Pharmacodynamics of Pimozide in Healthy Poor and Extensive Metabolizers of Cytochrome P450 2D6 (CYP2D6). Clinical Pharmacology \& Therapeutics, 65, 10-20. http://dx.doi.org/10.1016/S0009-9236(99)70117-7

[63] Risperidone Package Insert (2013) http://www.info.pmda.go.jp/go/pack/1179038C1027 $127 /$

[64] Trifluoperazine Package Insert (2013) http://www.info.pmda.go.jp/go/pack/1172008F1021_2_07/

[65] Bai, C.X., Kurokawa, J., Tamagawa, M., Nakaya, H. and Furukawa, T. (2005) Nontranscriptional Regulation of Cardiac Repolarization Currents by Testosterone. Circulation, 112, 1701-1710. http://dx.doi.org/10.1161/CIRCULATIONAHA.104.523217

[66] Shuba, Y.M., Degtiar, V.E., Osipenko, V.N., Naidenov, V.G. and Woosley, R.L. (2001) Testosterone-Mediated Modulation of HERG Blockade by Proarrhythmic Agents. Biochemical Pharmacology, 62, 41-49. http://dx.doi.org/10.1016/S0006-2952(01)00611-6

[67] Ramirez, A.H., Schildcrout, J.S., Blakemore, D.L., Masys, D.R., Pulley, J.M., Basford, M.A., et al. (2011) Modulators of Normal Electrocardiographic Intervals Identified in a Large Electronic Medical Record. Heart Rhythm, 8, 271-277. http://dx.doi.org/10.1016/j.hrthm.2010.10.034 
Scientific Research Publishing (SCIRP) is one of the largest Open Access journal publishers. It is currently publishing more than 200 open access, online, peer-reviewed journals covering a wide range of academic disciplines. SCIRP serves the worldwide academic communities and contributes to the progress and application of science with its publication.

Other selected journals from SCIRP are listed as below. Submit your manuscript to us via either submit@scirp.org or Online Submission Portal.
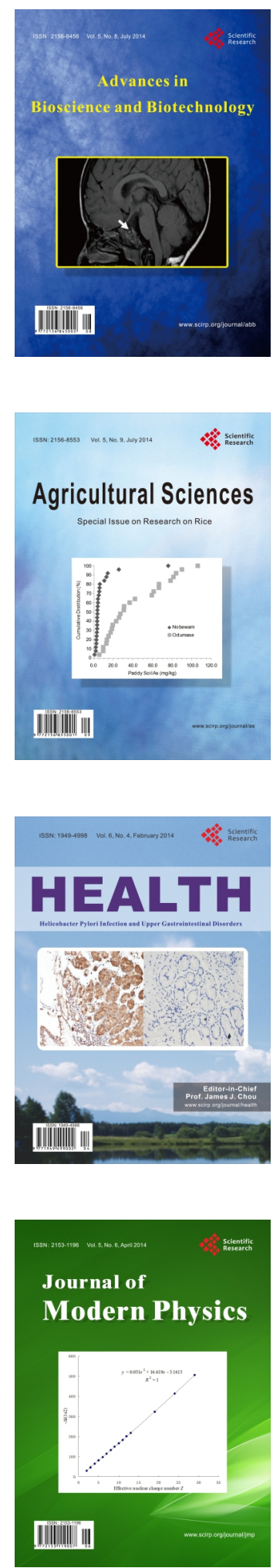
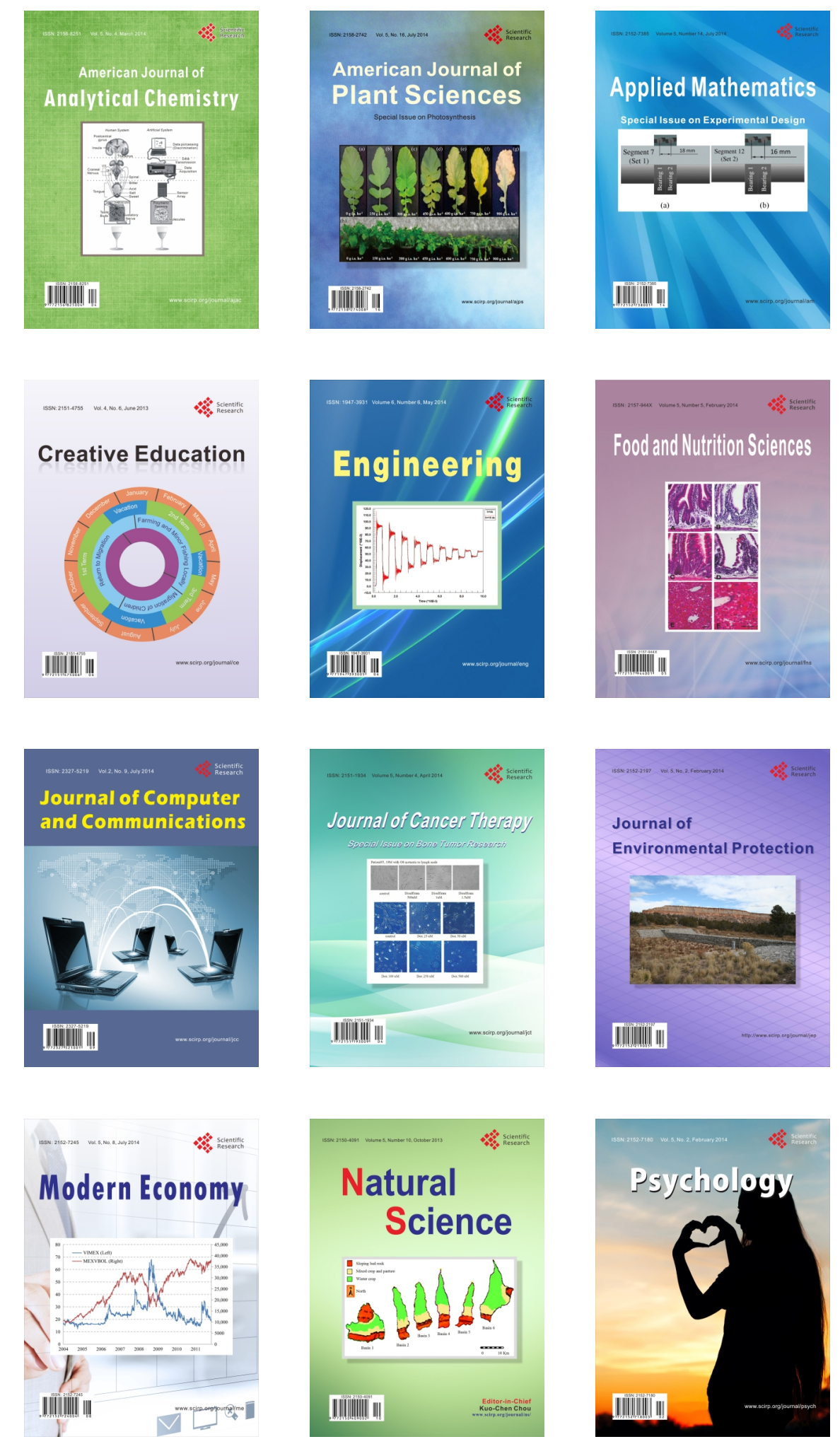